\title{
Human immunodeficiency virus (HIV) infection in men with penile carcinoma is associated with increased prevalence of human papilloma virus infection and younger age at presentation
}

\author{
SW Wentzel, ${ }^{1}$ LP Vermeulen, ${ }^{1}$ CA Beukes, ${ }^{2,3}$ J Thiart, ${ }^{2,3}$ G Joubert, ${ }^{4}$ J Goedhals ${ }^{2,3}$ \\ Departments of ${ }^{1}$ Urology, ${ }^{2}$ Anatomical Pathology and ${ }^{4}$ Biostatistics, Faculty of Health Sciences, University of the Free State, \\ and ${ }^{3}$ National Health Laboratory Services (NHLS), Universitas Academic Hospital, Bloemfontein, South Africa
}

Corresponding author: Professor SchalkWentzel (wentzels@ufs.ac.za)

\begin{abstract}
Background: We investigated the prevalence of HIV and human papilloma virus (HPV) infection in men with penile carcinoma.

Method: This retrospective study investigated all men with penile carcinoma at the Universitas Academic Hospital in Bloemfontein, South Africa (January 2000-December 2008). Patients' age, HIV status, histological type of carcinoma and evidence of HPV infection were recorded. Statistical analyses included Student's t-test and Fisher's exact test where appropriate (2-tailed p-value $<0.05$ indicated statistical significant).

Results: Among 65 patients (mean age 50.9 years, range 37-69), the most common histological type was squamous cell carcinoma $(80.0 \%)$. HIV status was known for 48 patients; $27(56.2 \%)$ were HIV-positive. The mean age at presentation was 43.7 years (range 26-69) years in the HIV-positive and 57.2 years (range 26-89) years in the HIV-negative group. Approximately $55 \%$ of HIV-positive and $24 \%$ of HIV-negative patients showed histological evidence of HPV infection $(\mathrm{p}=0.04)$. No significant difference was found with regard to histological type of carcinoma.

Conclusion: Patients with penile carcinoma had a high prevalence of HIV infection. The HIV-positive group were significantly younger at presentation, with a higher prevalence of HPV infection, suggesting that HIV may contribute to $\mathrm{HPV}$-associated penile cancer at a younger age.
\end{abstract}

Key words: penis; carcinoma; human immunodeficiency virus (HIV); human papilloma virus (HPV)

S Afr J Surg 2018;56(3) http://dx.doi.org/10.17159/2078-5151/2018/v56n3a2075

\section{Introduction}

Malignant neoplasms of the penis account for less than $0.5 \%$ of all neoplasms in males and $3 \%$ of all genitourinary cancers in western countries. ${ }^{1}$ However, there is 3 to 4 fold increase in low or middle income countries such as Uganda, Brazil, Jamaica, Mexico and Haiti where penile carcinoma represents $10-12 \%$ of all urogenital malignancies. ${ }^{1}$

Squamous cell carcinoma (SCC) is by far the most common type of penile cancer. ${ }^{1}$ The mean age of men with SCC of the penis varies from 55 to 63 years in studies from Europe and the United States of America, and the condition is rare in men under 40 years of age. ${ }^{1,2}$ Factors associated with an increased risk include lack of neonatal circumcision, poor hygiene, phimosis, smoking and viral infection. ${ }^{1,3}$ Human papilloma virus (HPV) is present in $15-80 \%$ of patients with primary penile cancer, and is thought to be the cause of $50 \%$ of all penile carcinomas. $^{3}$
SCC of the skin, oral cavity, epiglottis, oesophagus, lung, anorectum and cervix has been reported in patients infected with the human immunodeficiency virus (HIV). ${ }^{4}$ However, very few cases of HIV-associated invasive SCC of the penis have been reported in the literature. ${ }^{5}$

In view of the high prevalence of HIV infection in South Africa, the aim of this study was to determine the prevalence of HIV-positivity in men with SCC of the penis treated at our institution, and to determine its relationship to age at presentation and HPV infection.

\section{Method}

All cases of penile carcinoma histologically confirmed by the Department of Anatomical Pathology, University of the Free State, and National Health Laboratory Service between 
January 2000 and December 2008 were retrospectively reviewed. Haematoxylin and eosin (H\&E) stained slides and histopathology reports were retrieved from the departmental archives. The type of carcinoma and the presence or absence of HPV infection were confirmed by one pathologist (JG) who reviewed the histology slides. Evidence of HPV infection was defined as the presence of koilocytes and/or histological features of condylomata acuminata in the histopathology specimen (Figure 1). No molecular testing or genotyping was performed for confirmation of HPV infection. The pathologist was blinded to the HIV status of the study subjects. Ethnicity of the patients was self-declared.

HIV testing was performed by enzyme-linked immunosorbent assay (ELISA) of serum specimens. Data analysis was performed with Student's t-test and Fisher's exact test where appropriate, using GraphPad InStat software. Statistical significance was regarded as a 2-tailed p-value $<0.05$.

The study was approved by the Ethics Committee of the Faculty of Health Sciences, University of the Free State.

\section{Results}

In the period January 2000 through December 2008, 65 men were diagnosed with carcinoma of the penis: $52(80.0 \%)$ were SCC, 10 (15.4\%) verrucous carcinoma, 1 (1.5\%) undifferentiated and 2 (3.1\%) mixed carcinoma.

The mean patient age at diagnosis was 50.9 years (range 26-89 years). Of the 55 patients whose race was known, $52(94.5 \%)$ were black, two (3.6\%) white, and one $(1.8 \%)$ coloured. This reflects the demography of patients seen at our institution. Of the 48 patients whose HIV status was known, 27 (56.2\%) were HIV-positive. Histological evidence of HPV infection was present in 27 of the 65 cases (41.5\%) (Figures 1 and 2). The HIV-negative group when compared with the HIV-positive group had a significantly lower mean age at presentation and a significantly higher prevalence of HPV infection (Table 1). Figure 3 shows a haematoxylin and eosin (H\&E) stained section of infiltrating SCC of the penis.

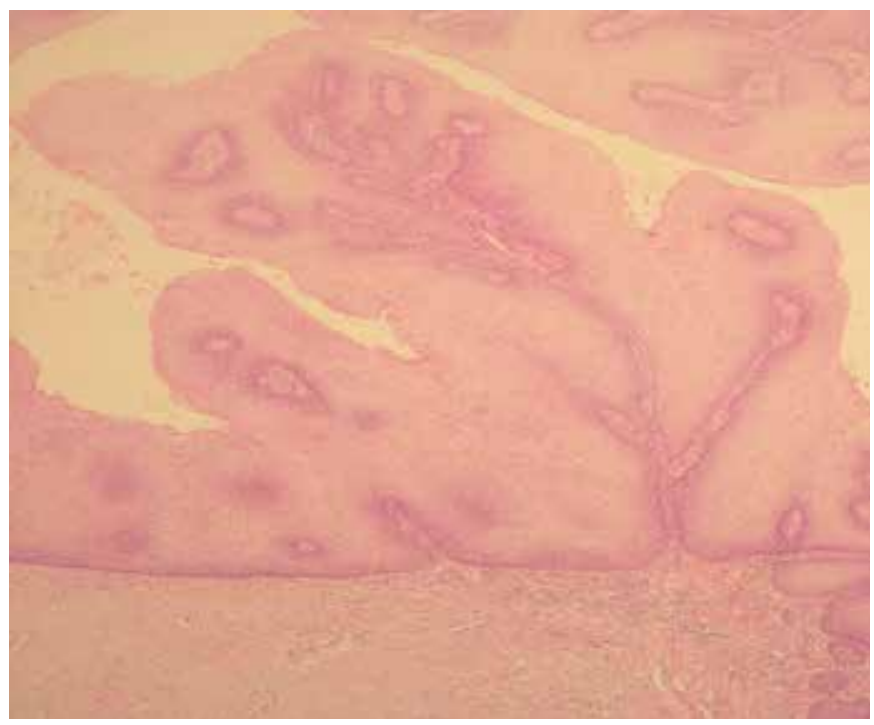

Figure 1. Haematoxylin and eosin (H\&E) stained section showing features of HPV infection (condyloma acuminatum) (10x magnification).

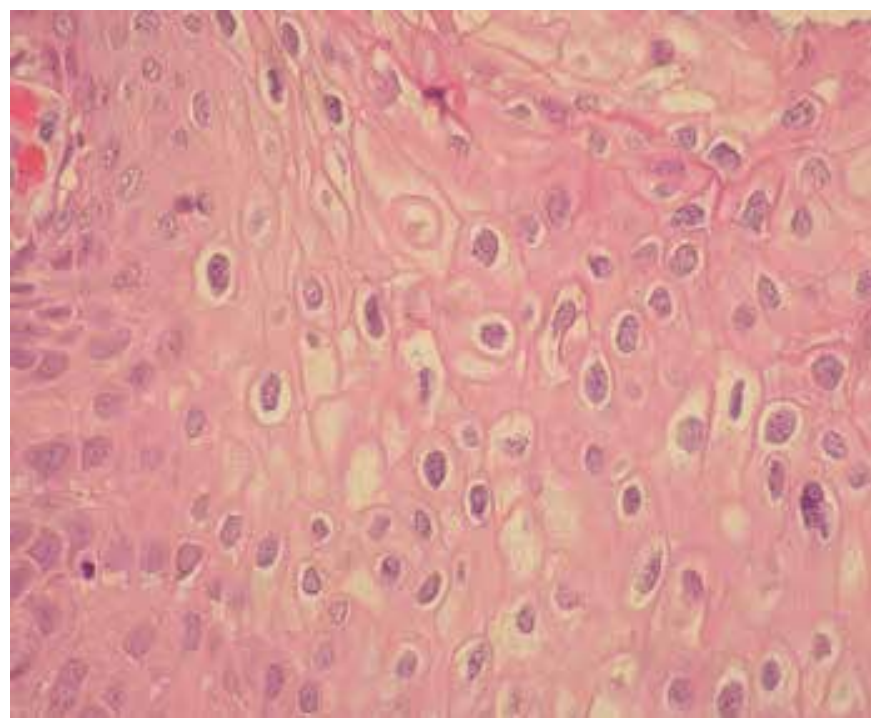

Figure 2. Koilocytes, the hallmark of HPV infection, with raisin-like nuclear membranes and a perinuclear halo (40x magnification).

Table 1. Association between HIV infection, patient age at presentation, HPV infection and histological type of penile cancer

\begin{tabular}{|c|c|c|c|c|c|}
\hline & \multicolumn{2}{|c|}{ HIV-negative } & \multicolumn{2}{|c|}{ HIV-positive } & p-value \\
\hline Mean & 57.2 & & 43.7 & & 0.05 \\
\hline Range & $26-89$ & & $26-69$ & & \\
\hline HPV on histology & $\mathrm{n}$ & $\%$ & $\mathrm{n}$ & $\%$ & \\
\hline HPV-negative & 16 & 76.2 & 12 & 44.4 & \\
\hline HPV-positive & 5 & 23.8 & 15 & 55.6 & 0.04 \\
\hline \multicolumn{6}{|l|}{ Histology } \\
\hline Squamous cell carcinoma & 17 & 89.5 & 21 & 77.8 & \\
\hline Verrucous carcinoma & 2 & 10.5 & 6 & 22.2 & 0.44 \\
\hline
\end{tabular}




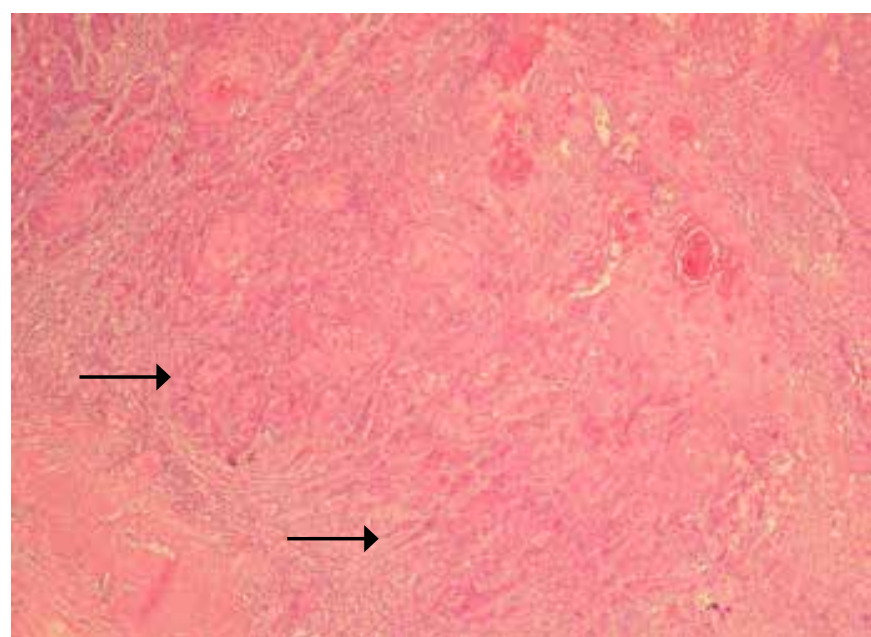

Figure 3. Haematoxylin and eosin $(H \& E)$ stained section of infiltrating SCC of the penis. Note arrowed the small irregular nests of tumour cells infiltrating the stroma. (10x magnification)

\section{Discussion}

It is well established that certain "high-risk" strains of HPV play an important etiological role in premalignant and malignant squamous cell lesions of the uterine cervix. ${ }^{6}$ Previous studies have shown that wives or sexual partners of men with penile carcinoma have a three-fold higher risk of cervical cancer. Male partners of women with cervical intraepithelial neoplasia have a significantly higher incidence of penile intraepithelial neoplasia as well as HPV infection. ${ }^{7}$

However, only about $30-50 \%$ of cases of infiltrating penile SCC are associated with HPV. ${ }^{5}$ Therefore, it is possible that penile carcinoma may develop along two different pathogenetic pathways: one that is associated with HPV and another that is unrelated to these viruses. ${ }^{6}$

Polymerase chain reaction (PCR) analysis can be performed to detect HPV $\mathrm{DNA}^{7}$ but due to financial constraints, it was not possible to perform PCR analysis on this cohort. Histologically, the presence of koilocytes and/or features of condylomata acuminata in biopsy material indicates the presence of HPV infection. However, lesions diagnosed as condylomata on histology can be negative for HPV DNA while HPV DNA can be detected in specimens which do not have the classical features of HPV infection. Hippeläinen et al. ${ }^{8}$ found $81.1 \%$ of condylomata acuminata were positive for HPV DNA using in situ hybridization and koilocytosis was the most powerful predictor of HPV-positivity with a risk ratio of $3.7 .{ }^{8}$ In our series $41.5 \%$ of patients had histological evidence of HPV infection, which is similar to the rates reported in other studies. ${ }^{7}$ The prevalence of HPV infection was significantly higher in the HIV-positive compared with the HIV-negative group (55.6\% vs $23.8 \%$ ). This suggests that HIV infection may facilitate the development of HPVassociated penile cancer. In anal squamous carcinoma it is thought that HIV infection increases the severity and length of HPV infection as immune compromised patients cannot clear the HPV infection as effectively as immune competent individuals. Additional factors promoting the genesis of anal squamous cancer include potentiation of expression of HPV E6 and E7 onco-proteins by HIV, the lack of Langerhans cells in the anal mucosa of HIV and HPV co-infected individuals and alteration of dendritic cells by HIV. How these mechanisms are involved in the genesis of penile squamous cancer have not been elucidated. ${ }^{9}$

Regarding the prevalence of HIV infection in South Africa, the 2008 National Antenatal Sentinel HIV and Syphilis Prevalence Survey noted an overall HIV prevalence of $29.3 \%$ among pregnant women 15-49 years of age, and a prevalence of $32.9 \%$ among pregnant women in the Free State Province. ${ }^{10}$ In our study cohort of men with penile carcinoma $56.2 \%$ were HIV positive, which indicates a substantially higher prevalence of HIV infection when compared with pregnant women.

Although the small size of this study is a limiting factor, the mean age of the HIV-positive group was significantly lower compared to the HIV-negative group (43.7 vs 57.2 years). This indicates that HIV infection may predispose to the development of penile SCC at an earlier age as can be seen in squamous carcinomas of the conjunctiva, cervix and lung., ${ }^{4,11,12}$ It is therefore important to perform a biopsy on men with suspicious penile lesions to exclude carcinoma, regardless of their age at presentation. All men diagnosed with penile carcinoma should be tested for HIV after they have received proper counseling. Additional larger studies which include molecular testing for HPV should be considered in future.

\section{Conclusions}

In this cohort of men with penile cancer the prevalence of HIV infection $(56.2 \%)$ was substantially higher than the reported prevalence among pregnant women $(32.9 \%)$ in the same geographical area. The HIV-positive compared with the HIV-negative group had a significantly lower mean age at presentation (43.7 vs 57.2 years) and higher prevalence of HPV infection $(55.6 \%$ vs $23.8 \%)$. This suggests that HIV infection may predispose to the development of HPVassociated penile cancer at a younger age.

\section{REFERENCES}

1. Mosconi AM, Roilia F, Gatta G, Theodore C. Cancer of the penis. Crit Rev Oncol Hematol. 2005;53(2):165-77. Available from: http://dx.doi.org/10/1016/j.critrevonc.2004.09.0062.

2. Carver BS, Mata JA, Venable DD, Eastham JA. Squamous cell carcinoma of the penis: a retrospective review of forty-five patients in northwest Louisiana. South Med J. 2002;95(8):8225. Available from: http://dx.doi.org/10.1097/00007611200208000-00008

3. Barnholtz-Sloan HS, Maldonado JL, Pow-Sang J, Giuliano AR. Incidence trends in primary malignant penile cancer. Urol Oncol. 2007;25(5):361-7. Available from: http://dx.doi. org/10.1016/j.urolonc.2006.08.029

4. Kestelyn PH, Stevens A-M, Ndayambaje A, Hanssens M, van de Perre P. HIV and conjunctival malignancies. Lancet. 1990;336(8706):51-2. Available from: http://dx.doi. org/10.1016/0140-6736(90)91562-O 
5. Aboulafia DM, Gibbons R. Penile cancer and human papilloma virus (HPV) in a human immunodeficiency virus (HIV)infected patient. Cancer Invest. 2001;19(3):266-72. Available from: http://dx.doi.org/10.1081/CNV-100102554

6. Krustrup D, Jensen HL, van den Brule AJ, Frisch M. Histological characteristics of human papilloma-virus-positive and -negative invasive and in situ squamous cell tumours of the penis. Int J Exp Pathol. 2009;90(2):182-9. Available from: http://dx.doi.org/10.1111/j.1365-2613.2008.00636.x

7. Pettaway CA, Lynch DF, Davis JW. Tumors of the penis. In: Wein AJ, Kavoussi LR, Novick AC, Partin AW, Peters CA (eds). Campbell-Walsh Urology, 9th ed. Philadelphia: W.B. Saunders, 2007; p. 96-6.

8. Hippeläinen MI, Syrjänen S, Hippelmäinen MJ, Saarikoski S, Syrjänen K. Diagnosis of genital human papillomavirus (HPV) lesions in the male: correlation of peniscopy, histology and in situ hybridization. Genitourin Med. 1993;69(5):346-51. Available from: https://www.ncbi.nlm.nih.gov/pmc/articles/

\section{PMC1195115/}

9. Marin-Muller C, Li M, Chen C, Yao Q. Current understanding and potential immunotherapy for HIV-associated squamous cell carcinoma of the anus. World J Surg. 2009:33(4):653-60. Available from: http://dx.doi.org/10.1007/s00268-008-9835-y

10. Department of Health, South Africa. 2008 National Antenatal Sentinel HIV and Syphilis Prevalence Survey. 2009 (accessed 18 April 2017). Available from: https://www.health-e.org.za/ wp-content/.../96942c4ee47b32cbc3ae06a00c1b81a1.pdf

11. Lomalisa P, Smith T, Guidozzi F. Human immunodeficiency virus infection and invasive cervical cancer in South Africa. Gynecol Oncol 2000:77(3):460-63. Available from: http:// dx.doi.org/10.1006/gyno.2000.5775

12. Koegelenberg CFN, van der Made T, Taljaard JJ, Irusen EM. The impact of HIV infection on the presentation of lung cancer in South Africa. S Afr Med J. 2016:106(7):666-8. Available from: http://dx.doi.org/10.7196/SAMJ.2016.v106i7.10737 